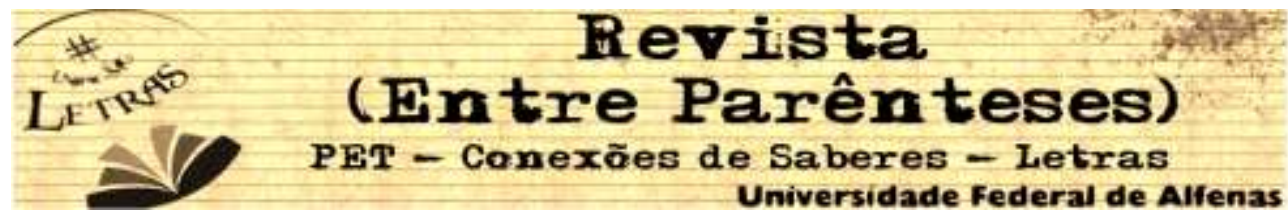

\title{
PRÁTICAS DISCURSIVAS ACERCA DA CRIANÇA E DA CRIMINALIDADE NO GÊNERO "NOTÍCIA": UMA ANÁLISE DA (RE)CONSTRUÇÃO DE IDENTIDADES
}

\author{
Sabrina Gomes Verola ${ }^{1}$ \\ Universidade Federal de Alfenas \\ sabrina_g85@hotmail.com \\ Rosângela Rodrigues Borges \\ Universidade Federal de Alfenas \\ rosangela.borges@unifal-mg.edu.br
}

\begin{abstract}
Resumo: Este trabalho traz uma análise qualitativa das práticas discursivas que envolvem criança e criminalidade no gênero notícia. Tem como objetivo analisar a representação desse sujeito partindo dos que promovem seus direitos. Apoiandonos na Análise Crítica do Discurso, será realizada uma abordagem de estudos dos representantes vinculados ao Poder Público e legislação atinente. Espera-se que os resultados deste trabalho possam esclarecer conceitos pré-estabelecidos em relação à criança e à criminalidade.
\end{abstract}

Palavras-chave: ECA; ACD; criança.

Resumen: Este artículo presenta unanálisis cualitativo de las prácticas discursivas que involucran niños y lacriminalidade nel género noticia. Tiene como objetivo analizar la representación del sujeto de la enunciación partido de los que promueven sus derechos. Así apoyándo se en el Análisis crítico del Discurso será realizado uma bordaje de estudios de los que se vinculan co nel poder público y lalegislación referida (o vigente). Se espera que los resultados de este estudio puedan aclarar conceptos prestablecidos em relación a losniños y la criminalidad.

Palabras clave: ECA, ACD, niños.

\section{Introdução}

Considera-se criança até os 12 anos de idade incompletos e adolescente aqueles que tenham entre doze anos a dezoito anos, segundo o Estatuto da Criança e do Adolescente (doravante ECA), legislação atinente a esse perfil a qual Ihes resguarda direitos fundamentais. Sendo assim, não importa qual criança seja, criança e

\footnotetext{
${ }^{1}$ Apoio: Programa de Educação Tutorial (PET) Conexões de Saberes - Letras/ Prodocência.
} 


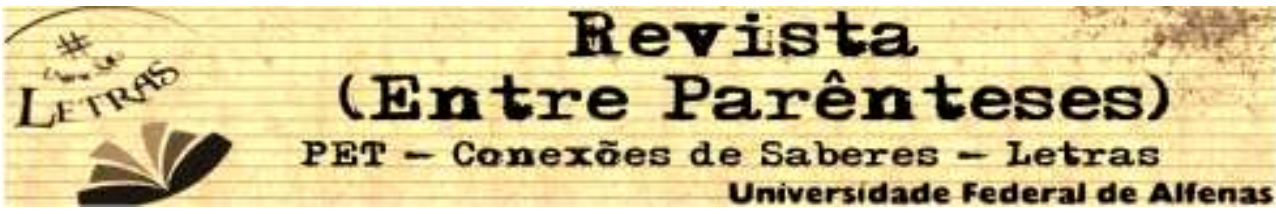

adolescente são protegidos e resguardados pelo ECA, o qual se funda em uma legislação maior, sendo ela a Constituição Federal de 1988. Existem, porém, algumas situações dentro desta temática que são consideradas importantes e que precisam ser analisadas, criança e criminalidade é uma delas.

Assim, apoiando-nos na Análise Crítica do Discurso (FAIRCLOUGH, 2001) e no conceito de discurso (FOUCAULT, 1996), procura-se observar, no gênero notícia, a representação da criança e criminalidade. Como objeto de análise, escolheram-se os gêneros textuais "notícia de jornal" e "entrevista" que aparecem em uma reportagem veiculada, em 2011, no Portal Terra (site de informações) na qual consta uma parte da entrevista feita com a Secretária Nacional de Promoção aos Direitos da Criança e do Adolescente.

Objetiva-se, com este trabalho, mostrar a ideologia (ORLANDI, 2001) subjacente ao discurso daqueles que resguardam os direitos do adolescente, e como esse direito é apresentado à sociedade, analisando ainda que práticas sociais são naturalizadas na e pela mídia acerca da criança e do adolescente, isto é, do menor infrator.

Com base na Constituição Federal de 1988, todos são considerados cidadãos, cada qual com direitos e deveres. Com a criança e o adolescente não é diferente, visto que ambos também são sujeitos de direitos e deveres. Sendo assim, é mais do que necessário conhecer também aqueles que os promovem e os fazem valer em cenários e situações das quais a criança e o adolescente podem se fazer presentes.

A partir de movimentos populares, iniciaram-se as lutas pelos direitos da criança e do adolescente, sendo eles mesmos os principais atores desse campo de conquista. Nesse sentido, Volpi 


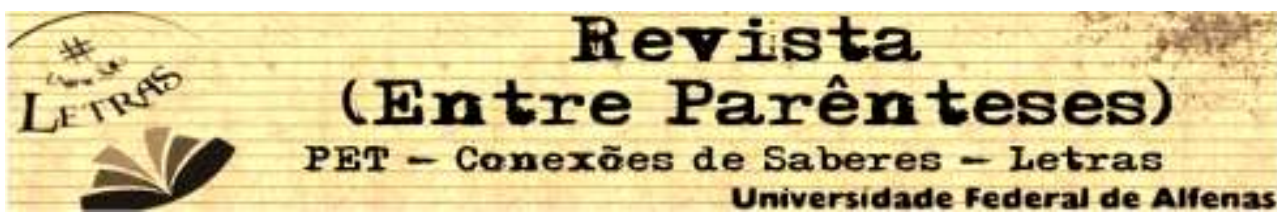

(2001) postula que, com a criação do Estatuto da Criança e do Adolescente, em 1990,

Supera-se uma antiga visão baseada naquilo que ela não é (não é capaz, não é maior e não é responsável), funda-se naquilo que é: criança, adolescente, sujeito de direitos, pessoa humana em condição peculiar de desenvolvimento que deve ser tratada com prioridade absoluta. (VOLPI, 2001, p. 2-3)

Refazendo uma trajetória histórica, é possível enxergar a luta de seres que foram marginalizados, oprimidos e calados durante um bom tempo. Seres humanos que por não terem alcançado certa faixa etária foram, de certa forma e em alguns contextos, excluídos da sociedade, ou até usados por essa mesma sociedade.

Observando tal pressuposto e percebendo a criança e sua luta por dignidade e respeito como algo necessário para a sociedade contemporânea, podemos observar que, na atualidade, ainda são travadas muitas batalhas envolvendo direitos e deveres da criança e do adolescente. Dessa forma, esses sujeitos precisam não apenas descontruir identidades que Ihes foram atribuídas, mas também precisam construir e reivindicar novas identidades tendo em vista os direitos e deveres que Ihes foram assegurados por meio do ECA e da Constituição Federal de 1988. Tal fato constitui-se um círculo, no qual direitos e deveres se entrecruzam, precisando ser reconquistados dia a dia. $\mathrm{O}$ contexto social em que se encontra a criança ou o adolescente, menores infratores, precisa ser analisado partindo daqueles que promovem o cumprimento e validade de seus direitos e da mídia que faz veicular discursos vários acerca desses menores.

Tendo como pressuposto a criança e o adolescente como sujeitos de direitos, tentar-se-á responder às perguntas de pesquisa: 


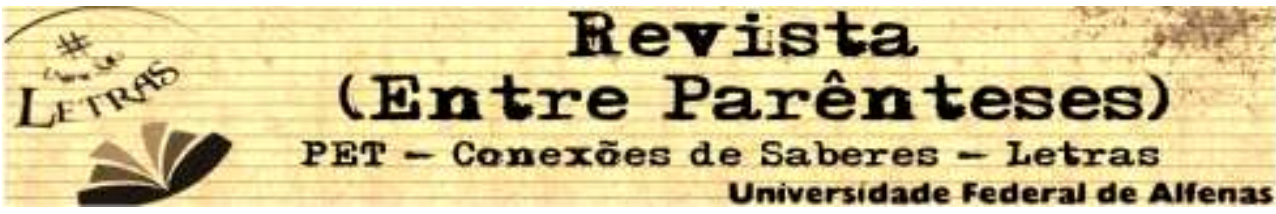

como se dá o discurso dos que promovem os direitos de crianças e adolescentes? em que esses se sustentam? qual é o papel da mídia nesse contexto?

\section{Criança e Criminalidade: representação social}

Como já foi mencionado, criança e adolescente são denominados como tal, segundo 0 art. $2^{\circ}$ do ECA. A criminalidade encontra-se relacionada ao crime, este por sinal é definido como um ato de violação contra alguma norma moral. Entretanto, crime, criminoso e criminalidade são termos relacionados, de acordo com a legislação brasileira, às pessoas capazes, maiores de 18 anos, que podem responder por seus atos.

Opondo-se a esses termos, reconhecem-se, pois, neste trabalho, os termos propostos pelo ECA, quais sejam, menor infrator e ato infracional, para designar, respectivamente, delinquente juvenil e crime. De acordo com a legislação atinente, o sujeito, menor de idade, considerado pelo ECA como criança ou adolescente, é nomeado de menor infrator para indicar que, de alguma forma, esse sujeito transgrediu uma norma moral.

Percebe-se, já de início, que o legislador, representando o Estado, nomeia, representa esse sujeito tentando protegê-lo tendo em vista que ainda é um sujeito/pessoa em formação. Assim, determina que as representações acerca da criança devem ser realizadas da forma com que se respeitem seus direitos e com que não se agrida a integridade moral desse sujeito. Dessa forma, procura o Estado proteger a criança ou o adolescente, que passa por um processo de reeducação, de ser vítima de conceitos préestabelecidos e pré-construídos pela parcela da sociedade que não compreende a situação do menor infrator ou que desconhece não só 


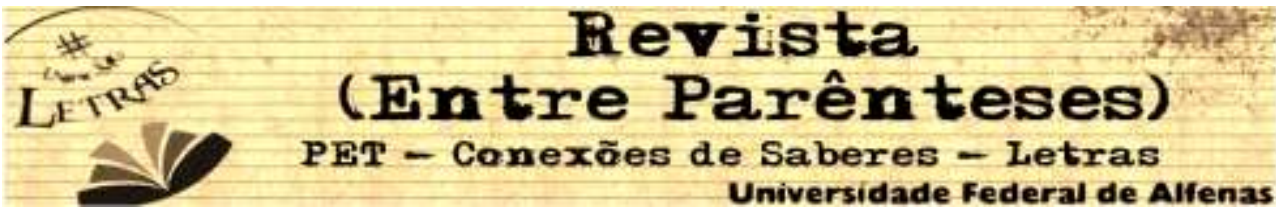

a legislação, mas o dever da sociedade de garantir também os direitos dele.

\section{Construção do conceito de infância}

Quando o indivíduo percebe que habita em um mundo no qual é preciso respeitar os direitos dos outros e cumprir seus deveres, ele passa a experimentar os valores e regras morais que existem na sociedade. Com isso, torna-se também um sujeitocidadão, acostumado e motivado a respeitar leis, instituições e esferas de poder. Em relação à criança e ao adolescente, o ECA os define e representa como sendo portadores de todos os direitos fundamentais, como se verifica no Art. $3^{\circ}$ :

A criança e o adolescente gozam de todos os direitos fundamentais inerentes à pessoa humana, sem prejuízo da proteção integral de que trata esta Lei, assegurando-se-lhes, por lei ou por outros meios, todas as oportunidades e facilidades, a fim de Ihes facultar o desenvolvimento físico, mental, moral, espiritual e social, em condições de liberdade e de dignidade. (BRASIL, 1990)

Com base nesse artigo do ECA, temos uma definição de que a criança e o adolescente são, à luz da legislação, sujeitos de direitos, sendo esses inerentes a qualquer pessoa humana, não podendo ninguém outorgá-los a não ser o próprio sujeito.

As concepções do que seja o termo infância no Brasil nem sempre foram vistas dessa forma. Antes que fosse conquistado esse espaço de 'direitos', foi preciso rever o próprio conceito de sujeito, aqui definido como um indivíduo capaz de conviver e de transformar o ambiente que está.

Utilizando-nos de uma retrospectiva histórica, observamos que a infância nos tempos de colônia era uma fase em que o

$5 \frac{\text { Revista (Entre Parênteses) }}{\text { Volume 1, Número 1, } 2012}$




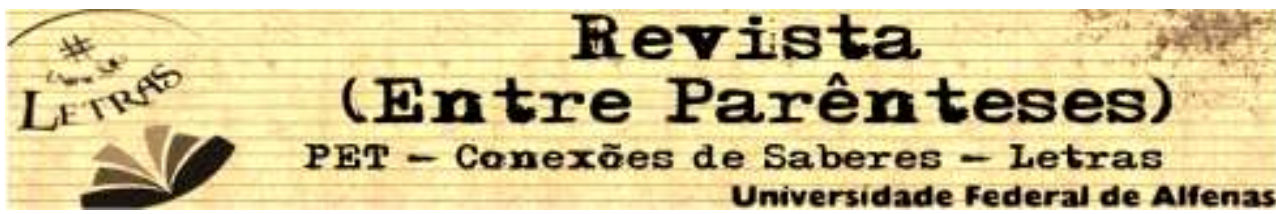

indivíduo era constantemente repreendido. Visava-se muitos vezes à opressão do indivíduo, no caso, a criança.

As crianças negras, intituladas como 'moleque levapancada', eram objetos das crianças brancas (os sinhozinhos e sinhazinhas). De acordo com Müller, o "pequeno escravo era tudo nas mãos dos sinhozinhos, o objeto de seus caprichos, o cavalo para montar, o amigo, o criado." (MÜLLER, 2001, p. 21).

Segundo Müller (2001, p. 22), no contexto da criança branca, a repreensão vinha dos pais, tios, padre e de todos que estavam a sua volta, e que, de alguma forma, achavam-se na condição de the impor/exigir certa autoridade. Outro aspecto a ser considerado é da criança escrava que tinha toda sua dignidade e liberdade massacradas, sem direito à escolha, vivendo sob as rédeas de adultos que a utilizavam como simples objetos, valendose dela como força de trabalho, principalmente quando esta crescia.

Outro cenário se relaciona às crianças abandonadas, cujos pais, sem saber o que fazer com os filhos indesejados, deixavamnos nas ruas, em situações de risco social ou de saúde, ou ainda em instituições e abrigos. Tal fato remonta a Idade Média, quando foi criada a "roda", um lugar onde as mães (ou o pai, ou outra pessoa da família) deixavam os bebês que queriam abandonar. Esse dispositivo garantia o anonimato do expositor.

A roda se fixava no muro ou na janela de uma instituição. Ao deixar a criança na roda, o expositor puxava uma cordinha que tocava uma espécie de sineta avisando que uma criança havia sido abandonada. Após serem deixados pelos próprios pais _ aqueles que deveriam garantir a sua proteção _, a criança crescia naquele ambiente, muitas vezes, sem carinho, atenção e amor.

As Casas de Rodas, instituições, Centros de Recuperação surgiram encobertos por uma falsa proteção, pois, na verdade, elas apenas respondiam ao anseio de uma parte da sociedade e do 


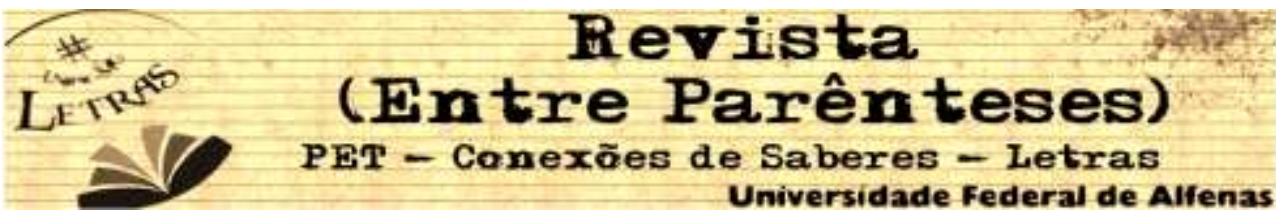

governo os quais ansiavam por se livrar daquilo que lhes parecia feio e escandaloso, de acordo com Muller (2001).

Desde tempos remotos, a criança teve seus direitos violados. Rotulados como menores e tratados como incapazes foram alvos das vontades, às vezes absurdas, dos adultos. De acordo com as reflexões de Volpi (1998), esperava-se que os adultos as resguardassem e protegessem, no entanto, a parcela da sociedade que buscou garantir esses direitos foram as próprias crianças, apoiados por adultos. A partir de movimentos populares, envolvendo meninos e meninas de rua, deu-se início à luta pelos direitos das crianças as quais mostraram que precisavam ser tratados, pela parte adulta, sem preconceitos ou inferiorização.

Com a aprovação do Estatuto da Criança e do Adolescente (ECA), marca-se, no Brasil, uma nova trajetória fazendo da sociedade, do governo e demais esferas do poder, responsáveis pelas crianças e adolescentes, conforme preconiza o próprio ECA:

Art. $4^{\circ}$ É dever da família, da comunidade, da sociedade em geral e do poder público assegurar, com absoluta prioridade, a efetivação dos direitos referentes à vida, à saúde, à alimentação, à educação, ao esporte, ao lazer, à profissionalização, à cultura, à dignidade, ao respeito, à liberdade e à convivência familiar e comunitária. (BRASIL, 1990)

Consolidando o conceito de infância e resguardando seus direitos, o ECA torna-se o principal mecanismo de legitimação dos direitos da criança. O Estatuto não se encontra sozinho. Hoje temos os Conselhos Tutelares, Conselhos de Direitos da Criança e do Adolescente, dentre outros. Todos esses órgãos são meios que visam à proteção e ao cumprimento dos direitos da criança e do adolescente. Assim, eles não podem se reduzir apenas a reuniões, é necessário que haja uma luta diária resguardando e garantindo uma

7 \begin{tabular}{c} 
Revista (Entre Parênteses) \\
\cline { 2 - 2 }
\end{tabular}




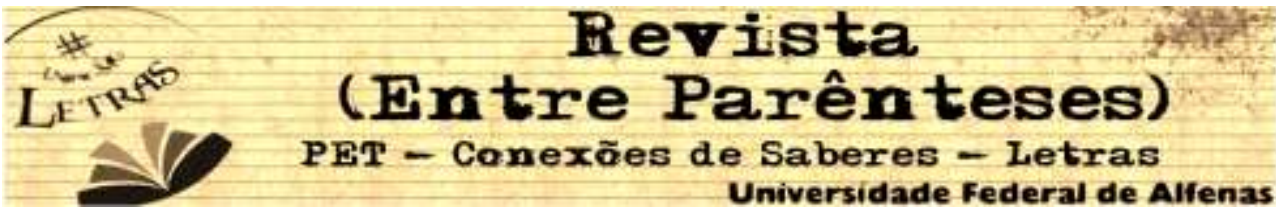

melhor qualidade de vida, social, física, familiar, profissional e psicológica, em especial às crianças e adolescente em risco social.

\section{Discurso e contexto social}

A partir de práticas discursivas envolvendo a criança e criminalidade contrapondo a uma construção de identidade, nota-se que este cenário é alicerçado/naturalizado pelo que chamamos de discurso, como prática social (FAIRCLOUGH, 2001). O discurso que nomeia crianças e adolescente como criminosos contribui para a construção de identidades desses sujeitos como delinquentes e indicando que, como criminosos, devem se submeter às mesmas penalidades de um adulto criminoso.

A mídia, em especial, ao materializar tais discursos, contribui para que uma parcela significativa da sociedade não compreenda a proposta do ECA e mais ainda, não assuma, como sociedade, a responsabilidade de deixar ou ter deixado crianças e adolescentes em situação de risco. Assim, o discurso passa a ser regido de tal forma que cada indivíduo interpreta uma sequência de ações sociais se tornando uma resposta, nem sempre positiva em se tratando de direitos humanos, a indagações de uma determinada sociedade.

Em relação ao discurso e à sociedade, Fairclough (2001) pontua que todo discurso é uma prática social, visto que traz em si características sociais, cognitivas ou históricas que proporcionam ao enunciador a produção do discurso. Ao mesmo tempo em que o discurso contribui de maneiras positivas, ele também traz traços negativos. 


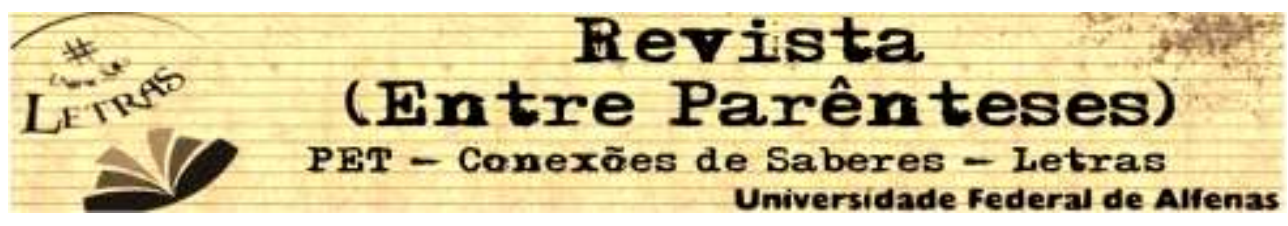

Em relação ao discurso e à sociedade, Foucault postula que

Em toda sociedade a produção do discurso é ao mesmo tempo controlada, selecionada, organizada e redistribuída por certo número de procedimentos que têm por função conjurar seus poderes e perigos, dominar seu acontecimento aleatório, esquivar sua pesada e temível materialidade. (FOUCAULT, 1996, p. 4.)

Assim, o discurso ao mesmo tempo em que está inserido na sociedade colaborando com conjuntos de ações aceitas, também se configura como um método de poder utilizado por minorias que dominam uma determinada parcela da sociedade, causando um efeito negativo de exclusão. Portanto, convém que os praticantes desse grupo, o grupo daqueles normatizam e defendem a causa de crianças e adolescentes, organizem e controlem discursos que podem contribuir para a construção de identidades negativas para os sujeitos que defendem e a manutenção de ideologias que há muito vem justificando a omissão da sociedade frente a esses problemas.

De acordo com Fairclough (2001), as ideologias são constituídas como significações da realidade, elas se materializam através do discurso. O discurso produzido reflete uma ideologia que se representa pela relação sujeito e história. Essas ideologias nascem na sociedade em relações de dominação entre classes sociais.

Após longos anos tendo seus direitos violados, a criança encontra legitimação através do ECA para validação e cumprimento de seus direitos, refletindo uma trajetória histórica de conquista e derivando em um ambiente de valores favoráveis a essas crianças. O discurso que envolve esta conquista os constitui como sujeitos sociais, sendo eles mesmos os responsáveis, até certo pondo, de modificar sua realidade. Segundo Orlandi, "com a transformação das 


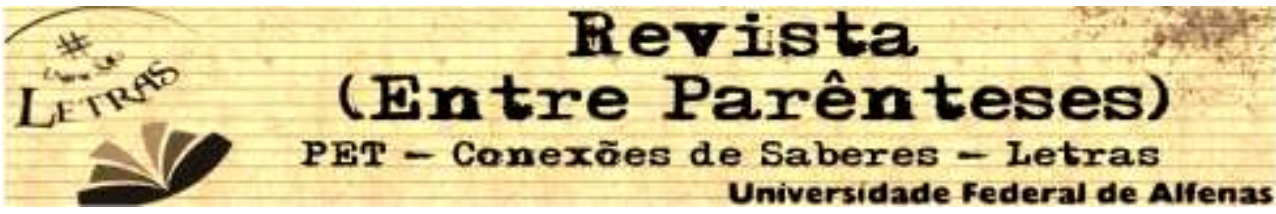

relações sociais, o sujeito teve de tornar-se seu próprio proprietário, dando surgimento ao sujeito-de-direito com sua vontade e responsabilidade." (ORLANDI, 2001, p. 51).

Com base no exposto, passamos, na próxima seção, à análise do corpus selecionado.

\section{Análise e discussão dos dados}

O texto, que se constitui objeto de análise, expõe, numa notícia de jornal, uma parte de uma entrevista dada ao Portal Terra acerca de atos infracionais cometidos por menores adolescentes. Para a análise, iremos nos ater aos enunciados proferidos por uma representante do poder público, aqui nomeada como C.S.C.

A análise dos enunciados da representante, que defende os Direitos da Criança e do Adolescente, no corpus selecionado, evidencia que a criança é vista como menor infrator, sujeita à medida socioeducativa. C.S.C. nomeia o sujeito em questão como criança, tendo-a sujeito de direitos, devendo ser tratada com prioridade.

A análise mostra ainda que se de um lado, criança é nomeada como criança, de outro, "aparece outra lógica com as crianças infratoras que têm que ir o mais cedo possível para o sistema sócio-educativo". Nesse sentido, criança e criminalidade são postas no mesmo patamar que adulto e criminalidade, decorrendo daí as representações dadas pela mídia e sociedade.

A criança é culpada por algo já naturalizado, isto é, é tida como delinquente infantil apenas e não como aquele que, sendo criança, necessita de cuidados. Esse discurso naturalizado (FAIRCLOUGH, 2001) provoca um apagamento na consciência de outros sujeitos da sociedade na medida em que culpados são 


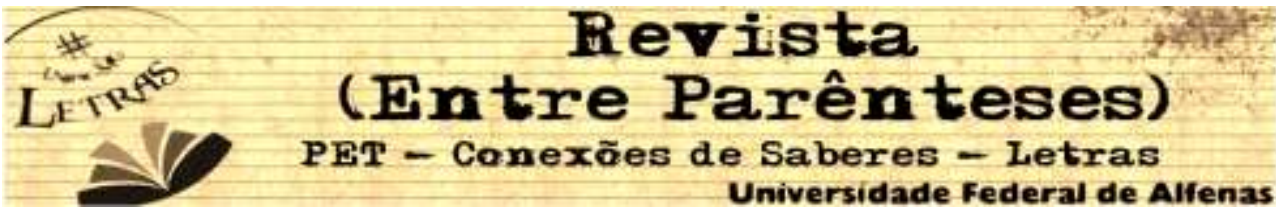

sempre os outros, criando, assim, rótulos naqueles que merecem respeito e atenção, principalmente porque ainda estão em processo de formação.

É nessa tensão entre direitos e deveres e criminalidade/ ato infracional que esse sujeito (a criança e o adolescente) se transformou em sujeito de direitos, identidade legitimada por órgãos públicos e amparada por uma legislação específica.

Por outro lado, a mídia, ao ressaltar a situação de crime, ao atribuir o aumento dos índices de criminalidade a crianças e adolescentes, constrói a identidade de criminoso, devendo, pois, receber o mesmo tratamento que um adulto receberia. Ainda que veladamente, a mídia instaura o discurso de o ECA vem provocando esse aumento dos índices de criminalidade. Para isso, a mídia promove, ao mesmo tempo, o apagamento de discursos acerca do papel do Estado, do papel da sociedade, da família que não conseguem garantir as condições mínimas para o menor infrator: educação, saúde, moradia e lazer.

Analisando a representação da criança no enunciado da entrevistada C.S.C, percebe-se que a criança é tratada como "menor infrator", estando sujeita à medida socioeducativa. Com o ECA, a criança e o adolescente passaram a ser tratados como sujeitos em situação peculiar de desenvolvimento e não mais como o "menor", que pressupõe o moleque, marginal, o que não tem capacidade, etc.. Nesse sentido, retomamos as considerações de Müller et. al., que salientam que

Substituído, após a promulgação do Estatuto da Criança e do Adolescente - (EC), por "Crianças e Adolescentes", porém ainda arraigado nas falas do poder e da mídia, o termo "menor" surge pleno de conteúdo e estigmas, usado normalmente para referenciar as práticas concretas, ou seja: menor, pivete, pobre, carente, fruto de desajustes, chegando a palavra menor às raias de uma 


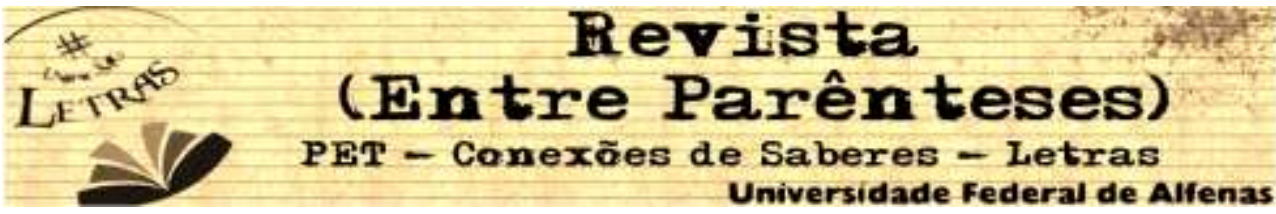

antipatia terminológica. (ASCIUTTI; KISHIMOTO, 2002, p. 196).

Hoje, o termo usado para se referir à criança e à criminalidade, é criança (ou adolescente) em conflito com a lei, sujeito a medidas socioeducativas, como dispõe o Artigo112 do ECA. Após a definição da terminologia, observamos que as escolhas lexicais usadas no corpus selecionado estão adequados aos termos legais usados para se referir à criança e à criminalidade.

$\mathrm{Na}$ análise, observa-se que a entrevistada C.S.O. faz menção à forma como a sociedade nomeia a criança, sendo ela um sujeito que ainda não alcançou a maioridade penal e que tem que ir mais cedo ao sistema socioeducativo. O discurso de C.S.O reflete uma preocupação com a criança que se constitui como um sujeito de direitos o que pode exemplificar que "[...] a ideologia faz parte, ou melhor, é a condição para a constituição do sujeito e dos sentidos." (ORLANDI, 2001, p. 46).

Quando, discursivamente, o tratamento dado à criança em situação de ato infracional acaba por equiparar essa criança a um adulto, desconsiderando sua faixa etária, constroem-se naturalizações por meio das quais não é problematizando as razões por que esta criança cometeu um ato infracional. Um adulto não pode ser tratado da mesma forma que uma criança, assim como a criança também não pode ser tratada como um adulto. Cada um necessita de tratamentos especiais, logo, a criança e o adolescente em conflito com a lei não poderão ser punido com medidas semelhantes.

Nessa perspectiva é possível observar na sociedade que, da parte de alguns, existe uma ideologia que discrimina e desrespeitam os direitos de crianças e adolescente que estão em risco. Essa forma, essa nomeação, representação desses sujeitos, menores infratores, também é retratada na mídia. Assim, a mídia representa 


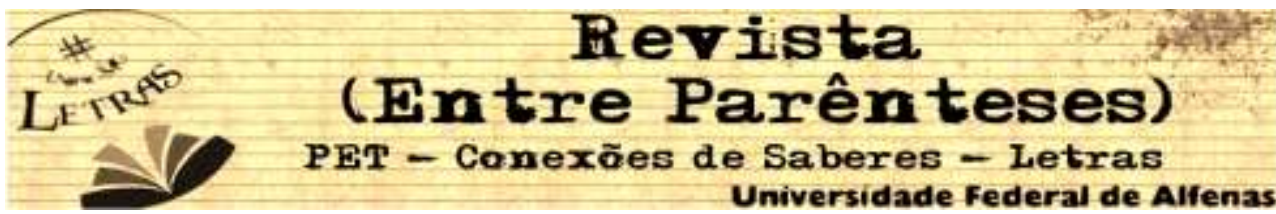

esse menor infrator como um sujeito que transgrediu alguma regra e por isso deve ser punido, esquecendo-se (propositalmente?) de esse menor ainda é uma criança.

Outro ponto que precisa ser observado está ligado diretamente a que levou a criança a cometer um ato infracional. Tomemos como ponto de análise a criança em situação de rua e partindo do pressuposto de que ela não foi para as ruas porque quis ou porque é mais confortável para ela, mas porque houve alguma motivação para que isso acontecesse. Se analisarmos o contexto social dessa criança observaremos que muitas se encontram na rua porque estão fugindo de algum problema, seja em casa com familiares, seja em abrigos e instituições que as receberam. Ressaltem-se, ainda, os casos em que a criança está na rua por necessita ajudar a manter a sobrevivência da família. Essa situação leva as crianças a fazerem da rua um ambiente no qual fixam moradia. Tal fato, nos últimos anos, tem merecido destaque na e pela mídia, como relatado a seguir:

As crianças e os adolescentes que fazem da rua seu espaço de sobrevivência e/ou moradia têm merecido nos últimos anos muito espaço na mídia e nenhuma resolubilidade da situação que as vitima, na medida em que a atuação, tanto do poder público (OGs) quanto da sociedade civil (ONGs), tem sido difusa e dispersa e feita através de práticas pontuais e segmentadas. (ASCIUTTI; KISHIMOTO, 2002, p. 194).

Mais do que relatar a situação na mídia, é necessário que seja dada a esta criança uma solução, uma oportunidade. As crianças têm sido tratadas como um grupo especial, mas só se tornaram assim porque as políticas públicas não conseguiram, ainda, dar alternativas que levem em conta suas reais necessidades.

Esse cenário de exclusão em que a criança está inserida reflete diretamente na sociedade. A qualquer lugar a que se vá 


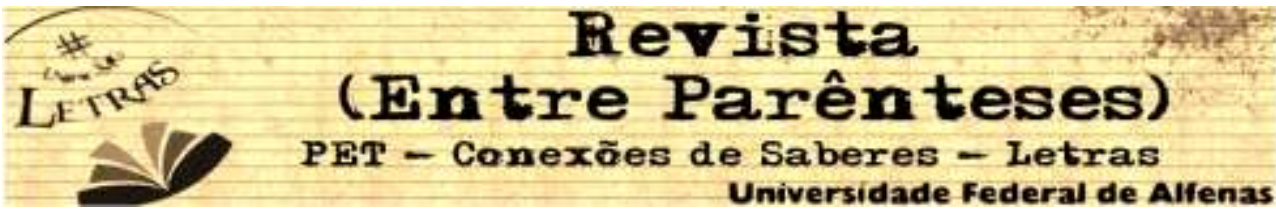

deparamos com crianças em roupas maltrapilhas, que nos cercam pedindo alguns trocados, algumas para comprar algo de comer, outras para dar aos pais que estão em casa ou até mesmo para manter algum vício. Isso é reflexo de uma sociedade que não consegue oferecer a essa parcela alguma oportunidade, logo a criança encontrará nesse meio em que está inserida uma possível alternativa, que a conduzirá à criminalidade, conforme a mídia, ou a atos infracionais conforme o ECA.

No discurso da entrevistada C.S.C, observa-se que ela faz menção a um sujeito histórico que teve todos os seus diretos violados e mesmo assim tem que ir o mais cedo possível para um sistema de privação de liberdade quando enuncia que "Antes da família, dos Estados e da sociedade fazerem um mea culpa, daquilo que se naturalizou, nós vamos penalizar novamente a criança ou o adolescente? Aquele que teve todos seus direitos violados, não convive mais com a família, que está fora da escola, que está sujeito a violência das ruas? Daí pegamos essa criança e aplicamos mais punição?" (TERRA, 2011).

Segundo a entrevistada, esse discurso naturalizado que envolve apenas dois lados da história precisa se renovar, pois o tratamento dado a essas crianças deve ser modificado. Essa modificação pode acontecer através de carinho, afeto, atenção e acolhimento. Como fatores essenciais para essa mudança, destacam-se a sociedade, instituições que as abrigam, e principalmente a família.

\section{Considerações finais}

A partir da análise realizada acerca da construção do conceito de infância, e observando as lutas das crianças. Nota-se que aos poucos e em meio a divergências, as crianças foram 


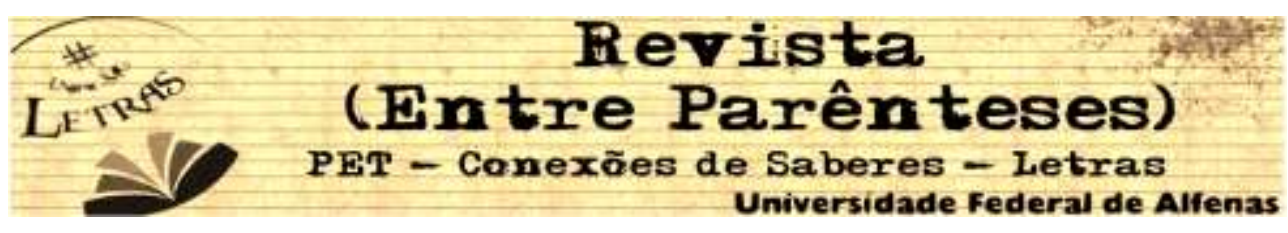

conquistando espaços, e com eles os seus direitos e deveres. Isso fez com que elas se tornassem sujeitos principais de uma história social que as colocaram como atores secundários.

Com base na enunciação da secretária Nacional dos Direitos da Criança e do Adolescente, enxergamos pessoas que lutam por dignidade e alternativas melhores para essas crianças. E, que mesmo cometendo algum ato infracional precisam ser tratadas com respeito.

Em um mundo em que tenta a todo o momento apenas procurar culpados, existem pessoas, que ao contrário desse desejo, procuram soluções e oportunidades para tais 'culpados'. Ainda existem pessoas que lutam por essas crianças e fazem de seus discursos práticas que intervém no real (ORLANDI, 2001, p. 95.).

Com isso, conclui-se que há a necessidade de problematizar conceitos pré-estabelecidos que diferenciem identidades construídas acerca da criança e criminalidade como forma de intervir na mesma sociedade que contribui para a existência de crianças na criminalidade.

\section{Referências bibliográficas}

ASCIUTTI, C. M; KISHIMOTO, C. Crianças e adolescentes e situação de rua. In: MÜLLER, R. V.; MORELLI, J. A. (Org.). Criança e adolescentes: a arte de sobreviver. Maringá: Eduem, 2001. p.191-220.

CRIANÇAS NO CRIME: secretária nacional critica estruturas. Disponível em: <http://noticias.terra.com.br/brasil/noticias/0,,Ol5313077-El306,00Criancas+no+crime+secretaria+nacional+critica+estruturas. html $\geq$. Acesso em: 28 ago 2011. 


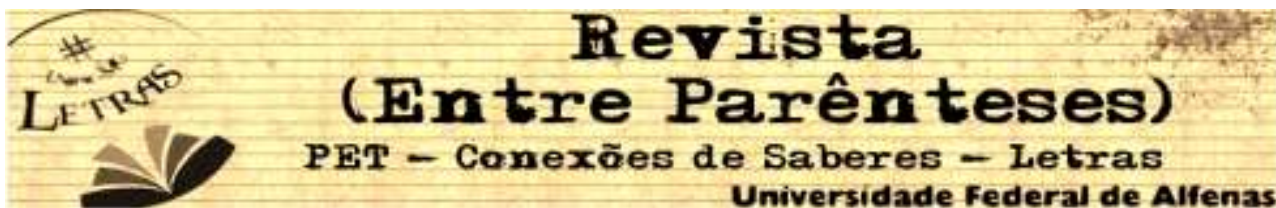

FAIRCLOUGH, N. Discurso e mudança social. Brasília:

Universidade de Brasília, 2001.

FOUCAULT, M. A Ordem do Discurso. São Paulo: Edições Loyola, 1996.

MÜLLER, R. V.; MORELLI, J. A. (Org.). Criança e adolescentes: a arte de sobreviver. Maringá: Eduem, 2001.

ORLANDI, E. P. Análise de Discurso: princípios e procedimentos. Campinas: Pontes, 2001.

ORLANDI, E. P. Sujeito, história e linguagem. Análise de discurso: princípios e procedimentos. Campinas: Pontes, 2001. p. 25-52

VOLPI, Mário. Crianças e adolescentes - de menores a sujeitos políticos. In: MÜLLER, R. V.; MORELLI, J. A. (Org.). Criança e adolescentes: a arte de sobreviver. Maringá: Eduem, 2001. p. 2-4 